\title{
Research and Application of Blended Learning in Distance Education and Teaching Reform
}

\author{
Chen Haijian ${ }^{\mathrm{a}}$, Huang Hexiao ${ }^{\mathrm{b}}$, Wang Lei ${ }^{\mathrm{c}}$, Chen Weiping ${ }^{\mathrm{d}}$, Ju Kunru ${ }^{\mathrm{e}}$ \\ Department of Information and Engineering, Shanghai Television University, Shanghai 200433, CHINA
}

\begin{abstract}
The new learning method of "Blended Learning" is widely applied. It integratess two typical forms of traditional classroom teaching and online teaching. How to unify them effectively? We explored the blended learning model .In the course of "Basic Program Design" we made an attempt for two years by using the example of teaching practice. We emphasized on the rates of attendance, including attendance in classroom and studying records on E-Learning. Student performance in classroom was recorded and immediately uploaded to E-learning platform. The teaching effectiveness was evaluated by thoroughly disserting in every detail of teaching, etc. Through the contrast, the quite good effect was obtained. This was the initial attempt to reform the learning model. In the future of teaching career, the effectiveness of blended learning model will be further explored in different courses.
\end{abstract}

Index Terms: Blended Learning, E-learning, Teaching Design, Teaching Reform, Learning Model

(C) 2011 Published by MECS Publisher. Selection and/or peer review under responsibility of the International Conference on E-Business System and Education Technology

\section{Introduction}

With the rapid development of educational information technology, distance learning has been updated to e-learning. At the early stage of development, there were some scholars who had believed that E-learning would completely replace the traditional classroom learning (face to face). From the market economy perspective, it was a successful learning model for many sides, but actually such a learning model was difficult to popularize and implement in the current society, at least not feasible now. In a recent survey, there were two questions which might also illustrate this point. Question one: what was your favorite reading material, an electronic version of the study (using a computer to read) or the printed version? More than $70 \%$ of the students preferred the printed version. Question two: if the university only provided CD-ROM (or online version) of learning materials, what did you think was feasible? More than $60 \%$ of the students thought it was infeasible. Through the reflection of E-learning, a new phrase "Blended Learning" firstly appeared. Blended Learning means a strategy of teaching method by integrated using different learning theories, different technologies and different ways of applications[1]. It integrates the advantages of both the traditional classroom teaching and the network teaching,

* Corresponding author:

E-mail address: ${ }^{\mathrm{a} x o c h j @ s h t v u . e d u . c n} ;{ }^{\mathrm{b}}$ huanghx@shtvu.edu.cn; ${ }^{\mathrm{c} w a n g l @ s h t v u . e d u . c n} ;{ }^{\mathrm{d}} \mathrm{chenwm@shtvu.edu.cn} ;{ }^{\mathrm{e} j u k r @ s h t v u . e d u . c n}$ 
combining their respective strengths, enhancing the teaching effectiveness. In this teaching process, teacher plays a leading role as a guide, inspirer and a controller. Students play the main part of the learning process with their initiative, enthusiasm and creativity. In recent years, institutions pursuing innovative pedagogical practices usually aim to develop new learning models encompassing different learning modes through two stages. The first stage is the mixed learning model, under which the mode mixing occurs at programming level. For the mixed model, courses under a program are taught in different but singular modes, either Distance Learning, Face To Face or E-Learning. After the mixed model, the second stage of development is the blended learning model, under which the mode mixing occurs at course level. For the blended model, individual courses are delivered in more than one mode in a combination of Distance Learning, Face To Face and /or E-Learning[2].

Shanghai TV University has engaged in distance education with a long history of 50 years. Firstly it started the opening education pilot project which the Ministry of Education ordered in 1998, and explored a new type of E-learning mode. So far, SHTVU has researched and summarized a lot of achievements, for example: "Guided Learning, Self-directed Learning and Supported Learning Mode" teaching mode(shortened as 3L),"System Management, Quality Management, Information Management" managing mode(shortened as 3M), "Conception System, Specification System, Organization System, Implementation of the System, Monitoring System, Assessment and Feedback System" Teaching Quality Assurance System(shortened as 6S). By the end of 2006, SHTVU deeply started the reform of teaching, and explored the blended learning model in course levels. Author organized a team, and successfully applied to Shanghai TV University "Basic program design" high-quality curriculum-building project. Everyone in the team had the practical teaching experience for many years and a set of blended learning models which used in engineering professionals had been put into research. In fact, utility of the mode has great effect on their study.

\section{Background analysis}

E-learning provide educational opportunities for learners with the objective of "everyone can learn" and life-long learning[3]. It also creates favorable conditions in which they could plan and adjust to make reasonable arrangement for their working and living situation, and alleviate the contradictions between work and learning, family and learning. With the further deepening of E-learning, the tremendous changes of learners are taking place. This is mainly reflected in three aspects[4]:(1) continued growth in the number of learners. The student's number of SHTVU has broken through 100,000 since 2003. The school has always maintained the size which the international distance education expert Daniel called as "mega-universities". (2) The composition of the learners' structure has changed. Among the current students, there are not only retirements, but also young just graduated from the school. There are not only first-class senior management of enterprises, but also migrant workers. There are not only learners for first academic, but also learners for second and third degree. There are not only well-known graduates of colleges and universities or full-time students, but also learners of master's degree or doctorate, and there are Hong Kong, Macao and Taiwan compatriots, and Paralympics' Games gold medalist, etc. (3) Learner's motivation was changing significantly. Nowadays in the situation of evaluating the diploma qualifications as the main social circumstances, the number of the learners who were not entirely for academic diploma and utilitarian purposes has been remarkably increased. From the existing situation of the investigation, the main purpose of SHTVU learners participating in the study was to obtain the diploma. However, from 2002 to 2007, there were more than 50\% students studying for "improve quality" and "work needs", this was a wonderful change. These changes of the E-learning had brought new challenges, the original model was a single model that could not meet the current needs of learners, it also attracted the attentions of many research institutions and researchers[5].

\section{Blended learning model of instructional design}

According to the analysis of the domestic and foreign literature, this paper argued that blended learning was: (1) An ideological and strategic; (2) E-learning and face-to-face learning mixed; (3) Multiple-level blended; 
Combination of learners, teachers, managers and technical personnel, etc. As we all know, a very strong practical computer courses has a close knowledge chain, it is difficult to achieve teaching objectives only with classroom teaching or e-learning, therefore, To explore blended learning model in the computer courses teaching is the task we are duty-bound. The research team in the "basic program design" of this teaching practice made a preliminary trial, and summed up a series of influential factors of blended learning model which summarized for reference and discussion:

\subsection{Teaching documents}

Perfect teaching documents were an important basis for the teaching and guidance in organization and implementation, which including: course description, syllabus, teaching materials of information, reference materials, teaching rules, formative assessment rules, implementation details of the practice of teaching, guiding and counseling. Teaching face-to-face and online teaching should be taken into account when we write these teaching documents. It was necessary to get "guided learning", "self learning" and "supported learning" work closely together, not simply move the text by no means.

\subsection{Design the formative assessment and final exams as an integration}

Examination was a measure of teaching results. General examination results were a combination of the final examination results and formative assessment results. However, examination was not our goal. In the design of the integration process, many things should be taken into consideration, such as the knowledge points suitable for the formation assessment, the knowledge points suitable for the ultimate examination, the content and the forms which should be included in the formative assessment. The main examination was to guide the learners to study effectively and improve learning methods, including E-learning and face-to-face learning, the formation of the closed-loop process of teaching.

\subsection{Focus on attendance's rate}

Many people wondered why open distance education was concerning on "attendance's rate". First of all, open distance education refers to the open education model, not the so-called "no learning open". Second, "attendance's rate" included face-to-face attendance and online learning record. Open education did not emphasize the face-to-face attendance. You could study E-learning. However, if there was half-time absence in face-to-face situation, there was no record of e-learning, and then it was difficult to guarantee the quality of teaching. Therefore, in my opinion, "face-to-face attendance records plus e-learning" must amount to a certain number in order to participate in the ultimate examination. Many teachers in the forum had this consensus.

\subsection{Add guidance materials and study CD-ROM}

Computer programs' teaching needs "theory + practice". The main materials of a more general theory were not suitable for self-learning, but guidance materials which focused on the practice of teaching, were very suitable for the self-learners. This course provided guidance materials and CD-ROM, including learning courseware, video of operation, study assignments etc. These cases were selected carefully, like a block of small building blocks; the last case could be integrated easily and created a "big house" with other cases. Each case was equipped with video and the operation could be explained. All of them were really ideal for self-study.

\subsection{Add small courseware}

In the past, the courseware included much knowledge and needed long time to learn. According to a study, adults' learning time with focus was normally for about 10 minutes. If it was more than longer study time, 
efficiency was very low. Many small courseware were equipped for difficult knowledge in this course, time within 5 minutes, which greatly enhanced the student's interest in learning and enhanced learning efficiency.

\subsection{Teaching content combined with difficulties and simplicities}

As already analyzed, now the composition of the structure of the learner had changed, there were not only the learners with weak study basis, but also the ones with good study basis, so the design of teaching contents should be considered based on the content and complexity to match the different needs of learners, to avoid "Some students may not have enough, and some students may have too much." This brought challenges to teachers. Teachers should design a variety of contents for teaching and contents with deferent levels of a "package" type, so the students could choose on demand.

\subsection{Video recorded in classroom}

At present, all the E-learning provide video-on-demand courses, the video is a unified model of face-to-face, with the lack of attractiveness, virtually no updates. According to the survey, very few learners watched the video, and fewer learners finished watching the video. In the process of teaching this course, the author recorded all the teaching in classroom including students' performance and teacher-student interaction, and immediately uploaded these video to the E-learning platform. According to records on-demand analysis, not only the absent learners but also the learners present watched the video on the E-learning. This video had these advantages: (1) affinity, the learner was willing to watch; (2) because of the highly logic in this course ,many students had difficulties to understand the contents in the class and easily forget the contents after-school, so these video-on-demand contents could consolidate the knowledge; (3) an increase of active learning. Nowadays, the network institutions of Shanghai Jiaotong University and other networks organization are using this method.

\subsection{Online teaching}

Online teaching used network technology for distance learning activities, including real-time teaching and non-real-time teaching. Generally, online teaching including lectures, study, counseling, group discussions and other activities, was a supplement to face-to-face teaching. The interaction of online teaching between teachers and learners, between teachers, between learners, were very popular. Online teaching included not only a traditional BBS exchanges, also the whiteboard, Blog, Wiki, RSS and other technologies. This was the goal of web2.0, also the purpose of E-learning.

\subsection{Online testing}

Online testing provided objective and subjective questions and practical questions to form closed-loop learning. Some knowledge of point-based questions was made into the form of objective questions. Students were randomly distributed examination questions. After submitting the answers scores and comments immediately were given and the all historical records were preserved .Students could find their own weaknesses. This was very suitable for self-learning. This course could develop students' logical thinking ability. So it was necessary to provide e-learning platform for online submission of a subjective question function (specific features described below). Teachers' timely feedback should be submitted to enhance the enthusiasm of students, but this would also bring schools and teachers new problems and thinking, as many students and teachers could not be online for 24 hours a day. 


\subsection{Design homework assessment}

Computer programs need electronic assessment, when designing homework assessment. We should consider this particularity to prevent online plagiarism and low-cost copy, and assessments could not be operated as a way of earning score. Results of formative assessment were usually an important aspect of the success or failure of learning. With the character of high logic and theoretical knowledge connected in this course, the formation of effective management of assessment was very important. Our university developed a set of assessment submitting system, including: assessment release, operation to submit assessment, submit time control, virus scanning, content operation matching marking operation, scores of management.

In practice, the learner's studying needs and preferences were different and different learners had different ability and basic knowledge. Blended learning has the flexibility of learning mode. Blended learning made full use of the idea of an integrated method. It not only concerned about students' constructive meaningful knowledge and abilities, but also grasped the system of knowledge. It was more conductive to students for knowledge expansion and relocation.

\section{Application of blended learning model}

Computer science was one of engineering professionals in SHTVU. It had much greater learning difficulties than other professions, so the students who choose computer science as profession had the following characteristics: (1) computer-loving; (2) more motivated to learn; (3) learning perseverance. Their learning background, learning methods, and theoretical foundation had the larger difference. The current teaching was organized by classes, so a single model of teaching is very difficult to meet the needs of all learners. "Basis program design" was the basis course of computer science curriculum. If this course was not learned well, it would bring the bad affection to follow-up courses, or even affect the whole learning. From 2006, by using the above measures, the author had began to reform and explore the new teaching model "Blended Learning". As a result, the teaching and learning performance were significantly improved. Students' passing rate of exam gradually increased and the attrition rate decreased significantly (Figure 1) [6]. The wastage rate was depressing steadily. Because of effective teaching, enrollment was increased steadily. It ensured the size of the computer profession and the quality of the teaching. This blended learning model had been applied in other courses and promotion. In a number of surveys and seminars, the teaching content of computer science, teaching methods and the blended learning model were fully affirmed by the graduates.

It proved that blended learning model could be used in the computer science courses. In the study of the course, traditional classroom learning continues to play a particular role. E-learning could make up for the shortcomings of traditional classroom learning. It well maintained the integrity and continuity of teaching and learning. It made full use of teachers' guiding role. It also greatly facilitated the selection, utilization and sharing of digital resources.

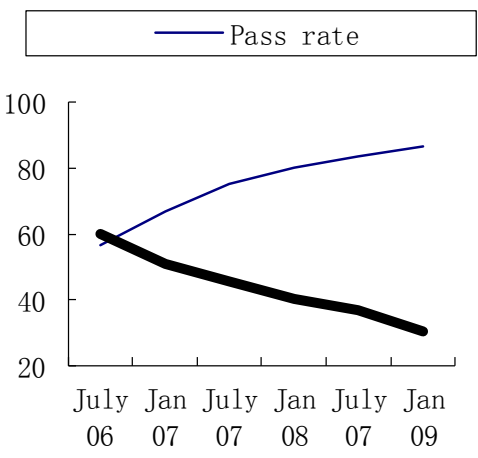

Fig 1. passing rate and the wastage rate chart 


\section{Conclusion}

Blended learning's emergence reflects a big improvement and change on education and teaching thinking of the international community. There is no good or bad, nor is a single model or standard in Blended learning model. Fitting is the best. In the process of transformation for the country teaching, to deal with the issue of teaching, it should be to seize the essence of using variety learning styles or create new learning methods to solve the problems. It is necessary to overcome the traditional and conservative habits of thinking, by combining the information technology with the integration of teaching, the teaching goal will be achieved eventually.

\section{Acknowledgment}

The work was supported by the project of Shanghai Higher education Academic society, Shanghai, China and the project (NO.GAQ1307) of Center Radio \& Television University, Beijing, China.

\section{References}

[1] He Kekang. The New Development of Educational Technology Theory from Blending Learning[J]. Journal of National Academy of Education Admimistrational,2005(09)

[2] Tian Shisheng,Fu Gangshan.Preliminary study of Blending Learning [J]. E-education Research,2004(07)

[3] Sir John Daniel,Ding Xingfu. Expanding Higher Education for the 21st Century:What Role for Open Learning[J]. Open Education Research,2006(12)

[4] Liu Li,Feng Lin,Zhang Aiwen.Distance education learners-the SHTVU practice of reading and research[J]. Distance Education in China,2006 (7, 8)

[5] David Wilkins. Learning 2.0 and Workplace Communities [DB/OL]. http://www.astd.org/LC/2009/0209_wilkins.htm

[6] Shanghai TV University student achievement over the years of statistical data[R],2009 